\title{
IUFOST2006/938 Effect of Plasticizers on Soy Protein - Beeswax Bilayer Films Prop- erties
}

\author{
G. Denavi ${ }^{\mathrm{a}}$, F. Speroni ${ }^{\mathrm{b}}$, A. Mauri ${ }^{\mathrm{a}}$ and M. Añón ${ }^{\mathrm{a}}$ \\ ${ }^{a}$ Centro Investigación y Desarrollo Criotecnología Alimentos, 47 y 116, 1900 La Plata, Argentina \\ bENITIAA, Rue de la Géraudière, BP 82225, 44322 NANTES Cedex 3, France
}

Soy protein films act as good barriers to oxygen, they have average mechanical properties, but their water vapour permeability (WVP) is too high. Lipid films have good barrier properties but are not resistant to mechanical damage. So the application of beeswax on the protein film in order to form a bilayer one takes advantage of those characteristics, producing a mechanically resistant bilayer film with lower WVP. The objective of this work was to evaluate the role of each component in the functionality of these bilayer films. As plasticizers play an important role in protein films behaviour, they were used as a variable to elucidate this objective. Protein films were obtained by casting from soy protein isolate (SPI) solutions ( $5 \% \mathrm{w} / \mathrm{v})$ containing sorbitol or glycerol as plasticizers, in different concentrations (1-5\%). These solutions were dried at $60^{\circ} \mathrm{C}$ for 3 hours. Then a thin molten beeswax lay was spread on the protein film at $80^{\circ} \mathrm{C}$, and cooled at ambient temperature. Moisture content, WVP, colour parameters (Hue-lab), mechanical properties (puncture and tensile tests) and structural properties were determined for bilayer and protein films. As was expected, the increment in plasticizer concentration increased the elongation, WVP and moisture content of protein films, while decreased their puncture and tensile strength. Glycerol acted as a stronger plasticizer than sorbitol, probably due to the lower amount of water that sorbitol films contained for the same drying conditions. The increased of plasticizers concentration show the same tendency on mechanical properties for bilayer films. No differences in strength and elongation were found between the bilayer film and its corresponding protein film (both with the same plasticizer type and concentration). WVP did not show differences among bilayer films with different plasticizer concentrations and between films with glycerol and sorbitol, but it was significantly lower in bilayers than in SPI film. About colour, bilayer films have an incremented yellowness (a higher a parameter) and they have a lower L parameter (opacity) than protein films. Thermal studies (DSC) showed that beeswax was crystallised in all the bilayer films, and proteins were totally denatured. These studies suggest that the protein film dominates mechanical properties, as differences were not seen neither in deformation nor in strength between films with or without the wax lay. And the lipid layer determines the WVP and the colour of the bilayer films, since both parameters do not vary with the type and concentration of plasticizer. 